\title{
Study on the Types of Deviant Workplace Behavior in Croatian IT Companies
}

\author{
Sanda RASIC JELAVIC ${ }^{1}$ and Marta GLAMUZINA ${ }^{2}$ \\ ${ }^{1}$ Faculty of Economics \& Business, University of Zagreb, Zagreb, Croatia \\ ${ }^{2}$ Combis, Zagreb, Croatia
}

Correspondence should be addressed to: Sanda RASIC JELAVIC; srasic@efzg.hr

Received date: 26 September 2020; Accepted date: 9 February 2021; Published date: 14 July 2021

Academic Editor: Katarzyna Gadomska-Lila

Copyright (C) 2021. Sanda RASIC JELAVIC and Marta GLAMUZINA. Distributed under Creative Commons Attribution 4.0 International CC-BY 4.0

\begin{abstract}
This paper deals with the concept of deviant workplace behavior. The paper presents the results of an empirical study on the types of deviant workplace behavior in Croatian companies in the Information Technology sector (IT). The difference in the occurrence of deviant workplace behavior by gender and age was analyzed, after which the correlation between the types of deviant behavior was examined. The results of the study showed a statistically significant difference in interpersonal deviance with respect to gender, i.e. male respondents are more prone to interpersonal deviant behavior in the workplace than women, whereas no statistically significant difference was found concerning organizational deviance. Regarding the age of the respondents, no statistically significant difference was found in any type of workplace deviance. Furthermore, a statistically significant correlation was found between two main types of deviance (organizational and interpersonal), although the correlation is weak. The limitations of the research are outlined as well as recommendations for future research.
\end{abstract}

Keywords: workplace deviance, age, gender, Croatian IT.

\section{Introduction}

In recent decades, there has been a growing interest among scholars in the topics of deviant workplace behavior. Therefore, the number of studies addressing issues such as fraud, vandalism, theft, lying, spreading malicious rumors, aggressive behavior and sexual harassment in the workplace has grown rapidly. There are multiple perspectives based on different understandings, interpretations and

Cite this Article as: Sanda RASIC JELAVIC and Marta GLAMUZINA (2021)," Study on the Types of Deviant Workplace Behavior in Croatian IT Companies", The Journal of Organizational Management Studies, Vol. 2021 (2021), Article ID 967208, DOI: 10.5171/2021.967208 
translations of the concept of deviant workplace behavior.

Deviant workplace behavior might have various causes, but almost always such behavior leads to adverse consequences, not only for the organization but also for individuals. The most common consequences are loss of motivation, stress, fear, increase in absenteeism, decrease in performance and productivity of employees, decrease in quality and service, as well as loss of reputation and performance drop of the organization. When work behavior breaches organizational norms, its consequences affect all levels of the organization, including the decision-making process, productivity and financial costs (Sims, 2010; Brown and Mitchell, 2010). Furthermore, deviant workplace behavior can negatively influence company's stakeholders such as clients, business partners, society, etc. Therefore, the problem of deviant workplace behavior is important for any human capitaldependent and oriented organization aiming to create an efficient and effective work environment (Norsilan et al, 2014).

Previous research has found that between $50 \%$ and $75 \%$ of employees are involved in some form of deviant behavior (Bennett and Robinson, 2000; Harper, 1990; Harris and Ogbonna, 2002), while more recent research shows that more than $90 \%$ of employees acknowledge engaging in some type of deviant workplace behavior (Marasi et al, 2018).

This paper starts with the definition of deviant workplace behavior, a classification of deviant workplace behavior and an overview about its causes. The next section presents the basic characteristics of the Croatian Information Technology (IT) sector. The following section presents the results of an empirical study of employees in Croatian enterprises in the IT sector, which examined the correlation between types of deviant workplace behavior and differences in workplace deviance concerning gender and age. The conclusion of the research, as well as the limitations, are provided at the end of the paper.

\section{Literature Review}

\section{Definitions and types of deviant workplace behavior}

In literature, various terms are used for deviant workplace behavior such as work deviance (Appelbaum et al, 2007), counterproductive behavior (Bennett and Robinson, 2000; Hollinger and Clark, 1983), work destructive behavior, organizational misbehavior (Vardi and Weitz, 2004; Brooks, 2012), etc. Deviant workplace behavior is defined as "a voluntary behavior of organizational members that violates significant organizational norms, thereby jeopardizing the well-being of an organization and/or its members" and "that has a potential to cause harm to the organization, to those within, and in doing so, violates significant performance-enhancing norms" (Robinson and Bennett, 1995). Organizational norms refer to a group of expected behaviors, languages, principles and postulates that allows one to work at an acceptable pace in the workplace (Awanis, 2006). Organizational norms are set by formal and informal organizational policies, rules, procedures and organizational culture, and are related to the standards of the organization. Therefore, these rules are not the system of absolute moral standards (Kaplan, 1975). In companies that experience deviant workplace behavior, employees either lack the motivation to adhere to the organizational norms or become motivated to violate those organizational expectations. Hogan and Hogan (1989) view organizational deviance as a syndrome of "organizational delinquency" that includes a wide variety of counterproductive acts such as theft, drug and alcohol abuse, lying, insubordination, vandalism, sabotage, absenteeism, and, according to their words, "offensive actions". These authors believe that employees who were engaged in certain types of delinquent actions are more likely to engage in others.

Hollinger and Clark (1982) categorized an employee's work deviance into a propertyrelated deviance (acquiring or damaging employer's property), and production-related 
deviance (violating organizational norms in terms of quantity and quality of the work performed). Mangione and Quinn (1974) propose a similar categorization into: counterproductive behavior related to property (intentional damage of employer's property) and deviance related to production (poor quality or low quantity production). An often cited classification (Robinson and Bennett, 1995; Bennet and Robinson, 2000) divides workplace deviance into: (1) organizational that can be production-related deviance, and is a less severe form of deviance (absenteeism, delayed or early leaving work, taking longer breaks, slower pace of work, waste of resources), and property deviance that is a more severe form of deviance (demolition or alienation of property, misrepresentation of working hours, theft, counterfeiting of accounts, etc.) and (2) interpersonal, which may be a political deviance that is a mild form of deviance (gossip, blame shifting, favoritism, unfair competition, etc.), and personal aggression, that is a more severe form of deviance (sexual harassment, verbal harassment, stealing from co-workers, sabotaging and threatening coworkers, etc.).

Two main types of workplace deviance, interpersonal and organizational, are interrelated according to previous empirical studies (Benet and Robinson, 2000, Lee and Alen, 2002; Dalal, 2005). Regarding differences in main types of workplace deviance by gender, a number of previous studies found that men were more often involved in deviant behaviors (Santos and Eger, 2014; Anvar et al, 2011; Alsksić et al, 2019; Naćinović et al, 2020; Appelbaum, Degiure \& Lay, 2005) and more often involved in aggression at work in comparison to women (Martinko, 2006; Griskevicius et al, 2009; Cross et al, 2011). In their empirical research, Chernyak-Hai et al (2018) found no Mean differences in individual and organizational deviance regarding gender, but differences were found in profiles coordinates; i.e. males were more often involved in certain items of direct aggression, and in organizational deviance items of a more severe form, whereby females were more often involved into indirect aggression items i.e. political deviance and in certain items of organizational deviance of a less severe form. Regarding the age, many previous studies found that the level of Work Deviant Behavior (WDB) is decreasing with the increasing age of employees (Hollinger, 1985; Pletzer, Oostrom \& Voelpel, 2017; Naćinović Braje et al, 2020).

\section{Causes of deviant workplace behavior}

Several theories, such as the theory of social exchange (Blau, 1964), the norm of reciprocity (Gouldner, 1960) and the theory of psychological contract (Rousseau, 1989) are often used to explain the link between responsible and undesirable organizational behaviors. The theory of social exchange is a relatively old theory in social sciences that has been developed and modified over time. It covers a number of models that have some common elements but also some specificities. Within the theory of social exchange, the basic assumption is that resources among parties are exchanged reciprocally. Social exchange refers to interdependent actions among parties based on a mutual exchange of resources (economic and socioemotional) and that create a relationship if they are repeated. Theorists who advocate the social exchange theory consider that in a workplace, a certain kind of social exchange between the employee and the organization occurs. When one party (organization) treats the other party (employee) in a good manner, the reciprocity norm obliges the other party (employee) to reciprocate a positive treatment (Gouldner, 1960) and vice versa. Desirable initiation actions by organizations are those that facilitate organizational justice, organizational support, supervisory support, trust, etc. The reciprocal response by employees may include organizational citizenship behavior, commitment, trust, etc. The existence of advantageous and fair reciprocal exchanges may transform economic exchange relationships into quality social exchange relationships that are closer and with longer time horizons (Cropanzano et 
al, 2017). Reciprocity, based on fair initiation actions, tends to facilitate better harmony among parties especially if repeated in cycles. It is assumed that employees receive some social benefits and rewards in exchange for their hard work and loyalty to the organization (Rhoades and Eisenberger, 2002). On the other side, negative initiation actions may lead to negative reciprocating responses. Consequently, unfair treatment may deter the quality of social exchange relationship and make employees prone to workplace deviance (El Akremi et al, 2010; Biron, 2010). A psychological contract refers to an employee's belief in mutual obligations between the individual and the organization. Such psychological contract can be relational or transactional and is seen as a strong determinant of behavior in organizations. A breach of the psychological contract often results in intense negative emotions such as anger (Rousseau, 1989). Negative emotions can also be reflected in undesirable organizational behaviors. In their model, Spector and Foxa (2002) explain that affect (emotions) evoke "tendencies for action" that can be constructive or destructive. The results of their research show that in a situation where a positive affect is caused, a responsible organizational behavior is more likely to occur, and vice versa.

Within the study of workplace deviance antecedents, scholars systematize a number of factors that are associated with the occurrence of such behavior. Alias et al (2013) categorize the causes of workplace deviance into three groups: a) individual factors b) jobrelated factors and c) organization-related factors. Individual factors capture certain employee's characteristics, feelings and cognition (including some personality traits, attitudes, values, mental health, etc.). Factors related to work include stress at work and powerlessness arising from a vague job description, work overload, lack of resources, and perception of working at a disrespected job. While factors associated with the organization include inadequate organizational culture and climate, insufficient organizational support, low levels of trust, organizational injustice, etc. (Chirasa and Mahapa, 2012).

Among the organization-related determinants, scholars emphasize the important role of the organizational culture in influencing deviant workplace behavior (Vardi and Weitz, 2004). Organizational culture usually interacts with other organizational-related factors, work-related factors and individual factors of workplace deviance to create or prevent employees' willingness to express deviant behavior. Formal organizational rules and procedures are in accordance with corporate culture. Schein (1985) defined organizational culture as a set of beliefs, values and assumptions that are shared by the members of an organization. Sharing certain values, norms, assumptions, and goals among employees influences the dynamics of relationships among employees themselves, between employees and the organization and between the organization and its stakeholders (Hill and Jones, 2001). Schein (2004) noted that organizational culture is identified in relation to what things members of the organization should pay attention to, how they react emotionally, and what actions they should take. Different types of values within the organizational culture encourage different types of social exchange that implies an important role of the organizational culture in a distinctive type of an exchange relationship (Richard et al, 2009). Corporate culture can facilitate positive or negative types of behavior by influencing barriers to progress, as well as rewards and recognition programs (Austin and Guillaume, 2016; An and Kang, 2016). There are examples of organizational culture that support aggressive behaviors as a type of employee motivation (Valentine et al, 2015). To decrease the possibility of deviant workplace behavior, organizations should shape an adequate value framework and other cultural artifacts that will create a domain of favorable work environment.

Although deviant workplace behaviors can be analyzed at the group level (Priesmuth et al, 2014), at the business unit level (Dunlop and 
Lee, 2004) and at the organizational level (Ermann and Lundman, 1978), in research studies, deviant workplace behaviors have generally been examined at the individual level.

\section{Croatian IT sector}

The basic indicators of the Croatian IT sector are taken from the Survey of the Croatian Chamber of Commerce (2018) related to the period from 2008 to 2017. According to this report for the year 2017, the Croatian IT sector is characterized by the following data: 1) the number of IT companies was 4.649 (9\% of the total number of companies in Croatia), with predominantly small-size companies $80 \%$ of IT companies had less than 5 employees; 2 ) the average monthly net salary was HRK 7.722 (44\% higher than the average net salary in Croatia); 3 ) the sector employs 28.347 workers $(3,2 \%$ of the total number of employees in Croatia); 4) the total revenue amounted to HRK 21,1 billion $(3,1 \%$ of the total revenue of the Croatian economy), whereby IT services account for about $70 \%$, trade of IT equipment $26 \%$, and the production of IT equipment/components about $3 \%$; 5) the economic value added amounted to HRK 6,7 billion $(4,8 \%$ of the total economic value added of the Croatian economy); 6) exports amounted to HRK 6 billion ( $4,8 \%$ of the total Croatian export), and the profit margin was 7,9\% (in comparison to the profit margin of the Croatian economy that was $-1,3 \%$ ).

Furthermore, it is interesting to present the movement of the basic indicators of the Croatian IT sector in the period from 2008 to 2017 (Croatian Chamber of Commerce, 2018): 1) the number of IT companies grew at an average annual rate of $8,1 \%$ (the average rate of the Croatian economy was 3,3\%); 2 ) the net salary grew at an average rate of 2,8\% (in comparison to the average net salary growth in Croatia of 1,8\%); 3 ) the number of employees grew at an average annual rate of $6 \%$ (while the average number of employees in the Croatian economy decreased annually by $-0,6 \%) ; 4$ ) the total revenue grew on an average rate of $3,8 \%$ (compared to the
Croatian economy, which decreased annually by $-0,5 \%) ; 5$ ) the economic value added grew annually at a rate of $6,7 \%$ (in comparison to the Croatian economic value added growth which was $0,9 \%$ a year); 6 ) exports grew at an average rate of $6,7 \%$ a year (while the average growth rate of the overall Croatian export was $4,4 \%), 7)$ productivity decreased by an average annual rate of $-2 \%$ (in comparison to the average rate of productivity growth in Croatia which was $0,1 \%$ ).

Regarding these data, it can be concluded that the Croatian IT sector is the propulsive sector that has been increasing faster than the overall Croatian economy in the observed period, except for productivity (measured by total revenue per employee) that has decreased in the observed period.

\section{Empirical study of deviant workplace behavior in Croatian IT companies}

\section{Research Methodology}

The aim of this paper was to investigate the occurrence of deviant workplace behavior, to examine the differences in deviant behavior by age and gender, and to determine the correlation between types of deviant workplace behavior in the Croatian IT sector. An empirical study was conducted in which the research population was employees of Croatian companies operating in the IT sector. Data were collected in 2019, and the survey was completed by 58 respondents. Participants were recruited based on a snowball technique through personal and professional contacts. This method is common in social research, especially if the research subject is connected with delicate issues (Etikan et al, 2016) such as workplace deviance. A survey questionnaire using a Google form was used as a data collection instrument. The questionnaire had 21 closedended questions, 2 of which covered demographics data (age and gender). The following 19 questions were designed to evaluate the occurrence of deviant behavior in the workplace. In constructing a questionnaire to investigate deviant behavior, the standardized questionnaire was 
considered (Bennett and Robinson, 2000). Interpersonal deviance was examined using 7 statements (items), while organizational deviance was examined using12 statements (items). Scale anchors were: 1 (never), 2 (once a year), 3 (twice a year), 4 (several times a year), 5 (monthly), 6 (weekly), and 7 (each day).

Empirical research was conducted in the following stages: (1) descriptive analysis of the sample; (2) analysis of differences in types of deviant workplace behavior by age and gender; and (3) analysis of the correlation between types of workplace deviance.

The analysis showed that the respondents are mostly employed in four medium-sized companies, with more than 50 employees in the IT sector. Among the respondents, $48 \%$ are women and $52 \%$ men (according to the latest 2011 census, the Republic of Croatia had $48.2 \%$ men and $51.8 \%$ women). The largest share of respondents is in the 18-25 age category, accounting for $55 \%$ of the sample, followed by the 26-45 age category, which makes up $38 \%$ of the sample. Only $7 \%$, or 4 respondents, are older than 45 years. None of the respondents are older than 65 years.

\section{Research Results}

At the beginning, the authors of this paper will present metric characteristics of the measurement scales for the types of workplace deviance, as a result of the reliability analysis.

Interpersonal deviance was measured by 7 items: INT_DEV_1 (Made fun of someone at work); INT_DEV_2 (Said something hurtful to someone at work); INT_DEV_3 (Made an ethnic, racial, or religious remark or joke at work); INT_DEV_4 (Cursed someone at work); INT_DEV_5 (Cheated on someone at work); INT_DEV_6 (Acted rudely toward someone at work); and INT_DEV_7 (Publicly embarrassed someone at work).

The results of the reliability analysis of the measurement scale for interpersonal deviance and the impact of individual items on the overall reliability are shown in Table 1. It can be seen from Table 1 that the scale "Interpersonal deviance" is in the area of excellent reliability. Reliability could be improved only slightly if the item I_DEV_1 "Made fun of someone at work" is removed. Therefore, the authors will use all seven items of this measurement scale.

Table 1: Measurement scale for interpersonal deviance - impact of individual items on the Cronbach's Alpha coefficient

\begin{tabular}{|c|c|c|r|r|}
\hline \multicolumn{5}{|c|}{ Item-Total Statistics: Total Cronbach's Alpha = 0,90 } \\
\hline $\begin{array}{c}\text { Items of } \\
\text { Deviance }\end{array}$ & $\begin{array}{c}\text { Scale Mean } \\
\text { if Item } \\
\text { Deleted }\end{array}$ & $\begin{array}{c}\text { Variance if } \\
\text { Item } \\
\text { Deleted }\end{array}$ & $\begin{array}{c}\text { Corrected } \\
\text { Item-Total } \\
\text { Correlation }\end{array}$ & $\begin{array}{c}\text { Cronbach's } \\
\text { Alpha if Item } \\
\text { Deleted }\end{array}$ \\
\hline INT_DEV_1 & 10,14 & 39,279 & 0,564 & 0,905 \\
\hline INT_DEV_2 & 10,64 & 37,814 & 0,814 & 0,869 \\
\hline INT_DEV_3 & 10,79 & 39,185 & 0,702 & 0,883 \\
\hline INT_DEV_4 & 10,45 & 35,971 & 0,797 & 0,871 \\
\hline INT_DEV_5 & 11,16 & 44,239 & 0,633 & 0,892 \\
\hline INT_DEV_6 & 10,91 & 38,957 & 0,789 & 0,873 \\
\hline INT_DEV_7 & 11,22 & 43,721 & 0,757 & 0,884 \\
\hline
\end{tabular}

Measurement scale for organizational deviance consisted of 12 statements:
OEG_DEV_1 (Taken property from work without authorization); ORG_DEV_2 (Spent 
too much time fantasizing or daydreaming instead of working); ORG_DEV_3 (Falsified a receipt to get reimbursed for more money than you spent on business expenses); ORG_DEV_4 (Taken an additional or a longer break than is acceptable at your workplace): ORG_DEV_5 (Come in late at work without permission); ORG_DEV_6 (Littered your work environment); ORG_DEV_7 (Neglected to follow your boss's instructions); ORG_DEV_8 (Intentionally worked slower than you could have worked); ORG_DEV_9 (Discussed confidential company information with an unauthorized person); ORG_DEV_10 (Used an illegal drug or consumed alcohol at work); ORG_DEV_11 (Put little effort into your work); ORG_DEV_12 (Dragged out work in order to get overtime).

The results of the reliability analysis of the measurement scale for organizational deviance and the impact of individual items on the overall reliability are shown in Table 2. It can be seen from Table 2 that the measurement scale for organizational deviance is in the area of very good reliability. Reliability could be further enhanced by deleting item ORG_DEV_12 "Dragged out work in order to get overtime." The result of the new reliability analysis without this item is shown in Table 3. After the item ORG_DEV_12 was deleted from the measurement scale for organizational deviance, a slightly higher, very good reliability was achieved and its Cronbach's Alpha coefficient is 0.80 . Since the elimination of any of the remaining eleven statements would not contribute to the increase of the Cronbach's Alpha, it will be used in this form in further analyses.

Table 2: Measurement scale for organizational deviance - analysis of the impact of individual items on the Cronbach's Alpha coefficient

\begin{tabular}{|c|r|r|r|r|}
\hline \multicolumn{7}{|c|}{ Item-Total Statistics: Total Cronbach's Alpha = 0,78 } \\
\hline $\begin{array}{c}\text { Items of } \\
\text { organizational } \\
\text { deviance }\end{array}$ & $\begin{array}{c}\text { Scale Mean if } \\
\text { Item Deleted }\end{array}$ & $\begin{array}{c}\text { Scale } \\
\text { Variance if } \\
\text { Item Deleted }\end{array}$ & $\begin{array}{c}\text { Corrected Item- } \\
\text { Total } \\
\text { Correlation }\end{array}$ & $\begin{array}{c}\text { Cronbach's } \\
\text { Alpha if Item } \\
\text { Deleted }\end{array}$ \\
\hline ORG_DEV_1 & 20,40 & 45,261 & 0,472 & 0,768 \\
\hline ORG_DEV_2 & 19,36 & 37,217 & 0,622 & 0,744 \\
\hline ORG_DEV_3 & 20,64 & 49,253 & 0,197 & 0,786 \\
\hline ORG_DEV_4 & 18,93 & 36,767 & 0,540 & 0,759 \\
\hline ORG_DEV_5 & 19,79 & 43,114 & 0,408 & 0,771 \\
\hline ORG_DEV_6 & 20,48 & 46,079 & 0,543 & 0,768 \\
\hline ORG_DEV_7 & 20,00 & 44,596 & 0,381 & 0,773 \\
\hline ORG_DEV_8 & 19,24 & 38,327 & 0,604 & 0,747 \\
\hline ORG_DEV_9 & 19,95 & 43,874 & 0,346 & 0,778 \\
\hline ORG_DEV_10 & 20,29 & 46,913 & 0,311 & 0,779 \\
\hline ORG_DEV_11 & 19,71 & 40,772 & 0,638 & 0,747 \\
\hline ORG_DEV_12 & 20,36 & 48,937 & 0,096 & 0,795 \\
\hline
\end{tabular}

Sanda RASIC JELAVIC and Marta GLAMUZINA, The Journal of Organizational Management Studies, DOI: $10.5171 / 2021.967208$ 
Table 3: Measurement scale for organizational deviance - Impact of items on the Cronbach's Alpha coefficient after deleting ORG_DEV_12

\begin{tabular}{|c|r|r|r|r|}
\hline \multicolumn{1}{|c|}{ Item-Total Statistics: Total Cronbach's Alpha = 0,80 } \\
\hline $\begin{array}{c}\text { Items of } \\
\text { organization } \\
\text { al deviance }\end{array}$ & $\begin{array}{c}\text { Scale Mean } \\
\text { if Item } \\
\text { Deleted }\end{array}$ & $\begin{array}{c}\text { Scale } \\
\text { Variance if } \\
\text { Item Deleted }\end{array}$ & $\begin{array}{c}\text { Corrected Item- } \\
\text { Total } \\
\text { Correlation }\end{array}$ & $\begin{array}{c}\text { Cronbach's } \\
\text { Alpha if } \\
\text { Item } \\
\text { Deleted }\end{array}$ \\
\hline ORG_DEV_1 & 19,02 & 43,491 & 0,484 & 0,779 \\
\hline ORG_DEV_2 & 17,98 & 35,877 & 0,610 & 0,759 \\
\hline ORG_DEV_3 & 19,26 & 47,564 & 0,190 & 0,798 \\
\hline ORG_DEV_4 & 17,55 & 34,532 & 0,581 & 0,766 \\
\hline ORG_DEV_5 & 18,41 & 41,475 & 0,409 & 0,783 \\
\hline ORG_DEV_6 & 19,10 & 44,410 & 0,543 & 0,780 \\
\hline ORG_DEV_7 & 18,62 & 43,117 & 0,366 & 0,787 \\
\hline ORG_DEV_8 & 17,86 & 36,612 & 0,616 & 0,758 \\
\hline ORG_DEV_9 & 18,57 & 42,390 & 0,335 & 0,792 \\
\hline ORG_DEV_10 & 18,91 & 45,378 & 0,295 & 0,792 \\
\hline ORG_DEV_11 & 18,33 & 39,172 & 0,639 & 0,759 \\
\hline
\end{tabular}

After the results of the reliability analysis, the differences in types of deviant workplace behavior, by gender and age are presented. A t-test was used to determine the behavioral differences on the dimensions of workplace deviance by gender, taking into account the results of the Levene equality test of variance in the sub-sample distribution (Male, Female). For the purpose of this test, the individual scores of the respondents on the seven statements of the dimension of interpersonal deviance were summed up, and the individual scores of the respondents on the eleven statements of the dimension of organizational deviance were also summed up. Two new variables were thus obtained: interpersonal deviance and organizational deviance. The results of the analysis are presented in Table 4.

Table 4: Difference in types of deviant workplace behavior by gender

\begin{tabular}{|c|c|c|c|c|}
\hline $\begin{array}{c}\text { Types of deviant } \\
\text { workplace behavior }\end{array}$ & $\begin{array}{c}\text { Scale Mean (Male) } \\
\text { Item-Total } \\
\text { Statistics }\end{array}$ & $\begin{array}{c}\text { Scale Mean (Female) } \\
\text { Item-Total Statistics }\end{array}$ & $\mathbf{t ( 5 6 )}$ & p-level \\
\hline Interpersonal deviance & 16,0 & 9,33 & 3,765 & 0,001 \\
\hline $\begin{array}{c}\text { Organizational } \\
\text { deviance }\end{array}$ & 20,93 & 19,83 & 0,592 & 0,556 \\
\hline
\end{tabular}

Table 4 shows that there is a statistically significant difference in interpersonal deviance with respect to the gender of the respondents $(\mathrm{p}<0.05)$, i.e. male respondents are more prone to interpersonal deviant behavior in the workplace than female. No statistically significant difference in organizational deviance was found between male and female respondents ( $p>0.05)$.

If the Mean of a particular type of deviant workplace behavior (Item-Total Statistics) is 
divided by the number of items used to measure it, an average mark of workplace deviance is calculated. For example, if the Mean (Male) for interpersonal deviance is divided by 7 (the number of items used to measure it), the average rating on these claims is 2.29. The average mark of interpersonal deviance, based on female respondents is 0.85 . The average mark of organizational deviance for male respondents is 2.86 , while female mark their deviance at 1.80 on average.

In the next step, t-test was used to determine the behavioral difference on the dimensions of deviance by age, taking into account the results of the Levene equality test of the variance of the sub-sample distribution (Age 18-25; Age 26+). For the purposes of this test, the individual scores of the respondents on the seven statements that make the dimension of interpersonal deviance were summed up, and the individual scores of the respondents on the eleven statements that make the dimension of organizational deviance were also summed up. Two new variables were thus obtained: interpersonal deviance and organizational deviance. Given that in the analyses of the difference in behavior, the variable "age" is used as a distinguishing criterion and that the third age category in the sample is very poorly represented, the variable "age" was recoded into two categories: $18-25$ years and 26 years upwards. The results of the analysis are presented in Table 5 . Table 5 shows that no statistically significant difference was found in either interpersonal or organizational deviance with respect to respondents' age ( $p>$ 0.05 ), i.e. respondents were equally prone or inclined to deviant behavior in the workplace regardless of their age.

Table 5: Difference in types of deviant workplace behavior by age

\begin{tabular}{|c|c|c|c|c|}
\hline $\begin{array}{c}\text { Type of deviant } \\
\text { workplace behavior }\end{array}$ & $\begin{array}{c}\text { Scale Mean } \\
\text { (Age 18-25) } \\
\text { Item-Total Statistics }\end{array}$ & $\begin{array}{c}\text { Scale Mean (Age } \\
\text { Item-) }\end{array}$ & t(56) & $\begin{array}{c}\mathbf{p} \text { - } \\
\text { level }\end{array}$ \\
\hline Interpersonal deviance & 12,09 & 13,12 & $-0,526$ & $\begin{array}{c}0,60 \\
1\end{array}$ \\
\hline $\begin{array}{c}\text { Organizational } \\
\text { deviance }\end{array}$ & 19,97 & 20,85 & $-0,472$ & $\begin{array}{c}0,63 \\
9\end{array}$ \\
\hline
\end{tabular}

If the Mean of a particular dimension of deviant behavior (Item-Total Statistics) is divided by the number of items used to measure that deviance, the average mark of deviance is calculated. For example, if the Mean for interpersonal deviance of younger respondents (18-25 years) is divided by 7 , the average rating on those items is 1,84 . The average mark of interpersonal deviance of older respondents (age 26+) is 1,87 . Concerning organizational deviance, the average rate of younger respondents (18-25 years old) is 1,82 , while older respondents (aged 26+) marked their organizational deviance with an average score of 1,90.

Furthermore, the authors were interested in the proportion of respondents who, according to self-assessment, had never been deviant in the workplace (Table 6). Specifically, Table 6 shows that the highest percentages of "Never" responses relate to items such as "Falsified a receipt to get reimbursed for more money than you spent on business expenses", "Publicly embarrassed someone at work", and "Cheated on someone at work" which can be classified as a more serious workplace deviance. On the other hand, the smallest percentages of "Never" is on answers for items such as "Taken an additional or longer break than is acceptable at your workplace," "Spent too much time at work fantasizing or daydreaming instead of working", and "Put little effort into your work", which can be classified as a minor deviance. 
Table 6: The proportion of "Never" responses in self-estimation of deviant workplace behavior (sorted from highest to lowest)

\begin{tabular}{|c|c|}
\hline Items of workplace deviances & $\begin{array}{c}\text { Proportion of } \\
\text { "Never" } \\
\text { responses }\end{array}$ \\
\hline $\begin{array}{l}\text { Falsified a receipt to get reimbursed for more money than you spent on } \\
\text { business expenses }\end{array}$ & $93 \%$ \\
\hline Publicly embarrassed someone at work & $83 \%$ \\
\hline Cheated on someone at work & $81 \%$ \\
\hline Littered your work environment & $79 \%$ \\
\hline Taken property from work without authorization & $76 \%$ \\
\hline Dragged out work in order to get overtime & $76 \%$ \\
\hline Used an illegal drug or consumed alcohol on the job & $71 \%$ \\
\hline Acted rudely toward someone at work & $69 \%$ \\
\hline Made an ethnic, racial, or religious remark or joke at work & $64 \%$ \\
\hline Said something hurtful to someone at work & $55 \%$ \\
\hline Cursed someone at work & $53 \%$ \\
\hline $\begin{array}{c}\text { Discussed confidential company information with an unauthorized } \\
\text { person }\end{array}$ & $53 \%$ \\
\hline Neglected to follow your boss's instructions & $52 \%$ \\
\hline Intentionally worked slower than you could have worked & $52 \%$ \\
\hline Come in late to work without permission & $45 \%$ \\
\hline Made fun of someone at work & $40 \%$ \\
\hline Put little effort into your work & $36 \%$ \\
\hline $\begin{array}{c}\text { Spent too much time at work fantasizing or daydreaming instead of } \\
\text { working }\end{array}$ & $33 \%$ \\
\hline $\begin{array}{c}\text { Taken an additional or longer break than is acceptable at your } \\
\text { workplace }\end{array}$ & $26 \%$ \\
\hline
\end{tabular}

In the next section of research, the interrelationships of the main two types of deviant workplace behavior: interpersonal and organizational are examined. A correlation analysis was performed to determine the interconnectedness of the two types of deviance. The results of the correlation analysis are shown in Table 7. Table 7 shows that the analysis confirmed a statistically significant correlation between the two types of deviance: interpersonal and organizational. However, their correlation is weak as these two variables share only $25 \%$ of the variance. 
Table 7: Matrix of correlations between the main types of workplace deviance

\begin{tabular}{|c|c|c|}
\hline $\begin{array}{c}\text { Types of workplace } \\
\text { deviance }\end{array}$ & Interpersonal deviance & Organizational deviance \\
\hline Interpersonal deviance & $\mathbf{1 , 0 0 0}$ & $0,499 *$ \\
\hline Organizational deviance & $0,499 *$ & $\mathbf{1 , 0 0 0}$ \\
\hline
\end{tabular}

\section{Conclusion}

Deviant workplace behavior can harm not only the organization and its employees but other stakeholders as well. Therefore, it is important to prevent these negative consequences by recognizing and preventing deviant behaviors at work. Many organizations depend on human capital, which is crucial in achieving competencies and competitiveness. Creating a supportive work environment without a fertile ground for deviant behavior can help companies in their path to success. The scientific literature describes a number of factors that are associated with deviant work behavior, such as individual factors, job-related factors, and organization-related factors. The theory of social exchange implies that managers should create a favorable internal environment with factors that improve organizational justice, organizational and supervisory support, adequate leadership styles, an adequate organizational climate and culture, etc. (organization-related factors). In addition, the existence of adequate work-related factors such as a clear job-description and job roles, clear job objectives, and sufficient resources help create a work domain that reduces deviance. Moreover, individual related factors should not be neglected within the process of employee selection and development. Understanding the role of these factors can help managers focus their attention on the identification of organizational weaknesses and improve them in order to create a desirable work environment that will diminish deviance.

The empirical research conducted in this paper confirmed the existence of various elements of the main two types of workplace deviance in Croatian IT companies. The results showed that employees were involved in various elements of both types of workplace deviance - interpersonal and organizational, although the average level of deviance is relatively low. Regarding the proportion of respondents who, according to self-assessments, had never been deviant in their workplace, results showed that the highest percentages of "Never" responses were related to the items that can be classified as a more serious deviance. On the other hand, the smallest percentages of "Never" answers were on the items that can be classified as a minor deviance. Additionally, the paper analyzed the relationship between different types of deviant workplace behavior and the differences between deviant workplace behavior by gender and age. The results show that there was a statistically significant correlation between the two types of deviant workplace behavior (interpersonal and organizational), but these two variables share only $25 \%$ of the variance, which makes that relationship weak. Furthermore, there was a statistically significant difference in interpersonal deviance with respect to the gender of the respondents $(p<0.05)$. Male respondents are more prone to interpersonal deviant behavior in the workplace than female. No statistically significant difference was found between men and women concerning organizational workplace deviance, ( $p>0.05)$. The average mark of interpersonal deviance for males is 2,29 , and for females is 0,85 - according to the scale from 1 (never) to 7 (each day). The average mark of organizational deviance for male respondents is 2,8 and for female respondents is 1,8 . Additionally, no statistically significant difference was found in either interpersonal or organizational deviance with respect to respondents' age ( $p>0.05)$. Respondents 
were equally prone or inclined to deviant behavior in the workplace regardless of their age. The reason could be due to the fact that only two age groups are compared (age 18-25 and age $25+$ ).

A relatively low level of both types of workplace deviance, found in this study, is in accordance with the results of a similar empirical research conducted in Croatian companies by (Aleksić et al, 2019) that indicated the same. The only difference is that the research of Aleksić et al (2019) showed that both types of deviance were slightly higher for male than for female respondents. Differences in interpersonal deviance regarding gender might have numerous reasons. The reason could be gender stereotypes that give men "alibi" to more often express negative feelings and aggression in comparison to women (Black, 1990), gender differences in job status, career and employment, perceived threat on employment status (Cherniak-Hai et al, 2018), differences in reward levels, etc. The authors agree with other scholars on additional reasons that could cause gender differences such as level of stress, level of self-esteem, level of confidence, differences in personality traits, different social roles and other factors of a broader social context. On the other side, the results regarding age are inconsistent with the research of workplace deviance in Croatian companies by (Naćinović Braje et al, 2020) which confirmed that workplace deviance decreases with the increase of respondents' age.

Although this study has produced interesting results, it is certainly worth considering the limitations of the research. The limitations of this empirical research stem from two main sources of possible bias: (1) relatively small sample size - results should be understood as indicative of assessing the reliability of measurement scales and the interrelationship of the variables used; and (2) respondents' bias - since respondents are asked to directly evaluate their own potentially deviant behavior on a given measurement scale, it must be taken into account that this is a subjective self-assessment, which may not correspond to reality. Specifically, the subject of the measurement is extremely sensitive. Admitting thefts, misuse of resources, unjustified delays at work, insults, physical assaults or harassment behaviors is not easy, which makes employees reluctant to admit such behaviors fearing the negative consequences that these admissions might have on them, although the survey is anonymous. In addition, people generally have a need to portray themselves in a better light, and this is particularly reflected in the subject of measurement. Likewise, respondents may have been deliberately dishonest in their self-assessment of deviant behavior, so it is likely that the incidence of deviant workplace behavior in this study is underestimated.

Recommendations for further research on this issue include: conducting empirical research on the occurrence of deviant behavior and the relationship between types of workplace deviance in other industries in Croatia or in other countries, that should include a larger number of respondents and be based on additional methodologies (such as profile coordinate methodology, etc.). Empirical research about various causes and consequences of deviant workplace behavior may be interesting to further explore the key factors of workplace deviance and their negative effects.

\section{References}

- Aleksić, A., Načinović, I. and Rašić Jelavić, S. (2019), 'Creating Sustainable Work Environments by Developing Cultures that Diminish Deviance,' Sustainability, 11(24), 1-13.

- Alias, M., Rasdi, R.M., Ismail and M., Samah, B. A. (2013), 'Predictors of workplace deviant behaviour: HRD agenda for Malaysian support personnel,' European Journal of Training and Development, 37(2), 161-182.

- An, Y. and Kang, J. (2016), 'Relationship between organizational culture and workplace bullying among Korean 
nurses, Asian Nursing Research,' 10(3), 234-239.

- Anwar, M. N., Sarwar, M., Awan, R.N. and Arif, M.I. (2011), 'Gender Differences in Workplace Deviant Behavior of University Teachers and Modification Techniques,' International Education Studies, 4(1), 193-197.

- Appelbaum, S. H., Degiure, K. J. \& Lay, M. (2005), 'The relationship of ethical climate to deviant workplace behavior,' Corporate Governance, 5 (4), 43-55.

- Appelbaum, S., Iaconi, G. and Matousek, A. (2007), 'Positive and negative deviant workplace behaviors: Causes, impacts, and solutions,' Corporate Governance: The International Journal of Business in Society, 7(5), 586-598.

- Austin, A.R. and Guillaume, O. (2016), 'Understanding organizational culture to transform a workplace behavior: Evidence from a liberal arts University,' Scholedge International Journal of Management \& Development, 3(4), 8996.

- Awanis, K. (2006), 'The relationship between deviance behavior among MARA employees in Northern Malaysia with its predictors,' Master thesis. Universiti Utara Malaysia. [Online]. [Assessed 20 August 2020]. Available: http://etd.uum.edu.my/69/2/awanis.p df

- Bennett, R. and Robinson, S. (2000), 'Development of a measure of workplace deviance,' Journal of Applied Psychology, 85(3), 549-560.

- Biron, M. (2010), 'Negative reciprocity and the association between perceived organizational ethical values and organizational deviance,' Human Relations, 63(6), 875-897.

- Black, K. S. (1990), 'Can getting mad get the job done?'' Working Woman,15, 8690.

- Blau, P. (1964), Exchange and power in social life, New York, Wiley.

- Brooks, G. (2012), 'Misbehavior, its dimensions, and relationship to commitment in organizations.' In Di Stefano, G., Scrima, F. and Parry, E.
(2017) 'The effect of organizational culture on deviant behaviors in the workplace,' The International Journal of Human Resource Management, May, 123.

- Brown, M. and Mitchell, M. (2010), 'Ethical and unethical leadership: Exploring new avenues for future research,' Business Ethics Quarterly, 20(4), 583-616.

- Chernyak-Hai, L., Kim, S-K. and Tziner, A. (2018), 'Journal of Work and Organizational Psychology,' 34(1), 4655.

- Chirasha, V. and Mahapa, M. (2012), 'An Analysis of the Causes and Impact of Deviant Behavior in the Workplace: The Case of Secretaries in State Universities,' Journal of Emerging Trends in Economics and Management Sciences, 3(5), 415421.

- Cropanzano, M., Anthony, E.L., Daniels, S.R. and Hall, A.V. (2013), 'Social exchange theory: A critical review with theoretical remedies,' Academy of Management Annals, 11(1), 1-38.

- Cross, C. P., Copping, L. T. and Campbell, A. (2011), 'Sex differences in impulsivity: a meta-analysis,' Psychological Bulletin, 137, 97-130.

- Dalal, R.S. (2005), 'A meta-analysis of the relationship between organizational citizenship behavior and counterproductive work behavior,' Journal of Applied Psychology, 90(6), 1241-1255.

- Dunlop, P. D. and Lee, K. (2004), 'Workplace deviance, organizational citizenship behavior, and business unit performance: The bad apples do spoil the whole barrel,' Journal of Organizational Behavior, 25(1), 67-80.

- Etikan, I.; Alkassim, R. and Abubakar, S. (2016), 'Comparison of snowball sampling and sequential sampling technique,' Biometrics \& Biostatistics International Journal, 3, 1-2.

- El Akremi, A., Vandenberghe, C. and Camerman, J. (2010), 'The role of justice and social exchange relationships in workplace deviance: Test of deviate 
model,' Human Relations, 63(11), 16871717.

- $\quad$ Ermann, M. D. and Lundman, R. J. (1978), 'Deviant acts by complex organizations: Deviance and social control at the organizational level of analysis,' The Sociological Quarterly, 19 (1), 55-67.

- Gouldner, A. (1960), "The norm of reciprocity: A preliminary statement,' American Sociological Review, 25 (2), 161-178.

- Griskevicius, V., Tybur, J. M., Gangestad, S. W., Perea, E. F., Shapiro, J. R. and Kenrick, D. T. (2009), 'Agress to impress: Hostility as an evolved context dependent strategy,' Journal of Personality and Social Psychology, 96, 980-994.

- Harper, D. (1990), 'Spotlight abuseSave profits,' Industrial Distribution, 767-772.

- Harris, L. C. and Ogbonna, E. (2002), 'Exploring service sabotage: The antecedents, types, and consequences of frontline, deviant, anti-service behaviors,' Journal of Service Research, 4(3), 163-183.

- Hill, C.W.L. and Jones, G.R. (2016), Strategic Management: An Integrated Approach, Cengage Publishers.

- Hogan, J. and Hogan, R. (1989), 'How to measure employee reliability,' Journal of Applied Psychology, 94, 273-279.

- Hollinger, R. C. and Clark, J. P. (1983), 'Theft by employees.' U: Marcus, B., Scholer, H. (2004), 'Antecedents of Counterproductive Behavior at Work: A General Perspective,' Journal of Applied Psychology, 89(4), 647-660.

- Hollinger, C. R. (1985), 'Acts against the workplace: Social bonding and employee deviance, Deviant behavior, 7(1), 53-75.

- Hrvatska gospodarska komora ( November 2018). Analiza hrvatske IT industrije 2008.-2017. [Online], [Retrieved 1 October 2020], Available: https://www.hgk.hr/documents/analiz ahrvatskeitindustrije5c372c1f59ebb.pd f
- Kaplan, H. (1975), Self-attitudes and deviant behavior, Pacific Palisades, Goodyear.

- Lee, K. and Allen, N. J. (2002), 'Organizational citizenship behavior and workplace deviance: The role of affect and cognitions,' Journal of Applied Psychology, 87, 131-142.

- $\quad$ Mangione. T. W. and Quinn, R.P. (1974) 'Job satisfaction, counterproductive behavior, and drug use at work,' Journal of Applied Psychology,1, 114-116.

- Marasi, S., Bennett, R. J. and Budden, H. (2018), 'The structure of an organization: Does it influence workplace deviance and its dimensions? And to what extent?', Journal of Managerial Issues, 30(1), 8-27.

- Martinko, M. J., Douglas, S. C. and Harvey, P. (2006), 'Understanding and managing workplace aggression,' Organizational Dynamics, 35, 117-130.

- Miner, K., Settles, I., Pratt-Hyatt, J. and Brady, C. (2012), 'Experiencing incivility in organizations: The buffering effects of emotional and organizational support,' Journal of Applied Social Psychology, 42(2), 340-372.

- Naćinović Braje, I., Aleksić, A., Rašić Jelavić, S. (2020), 'Blame It on Individual or Organization Environment: What Predicts Workplace Deviance More?,' Social Sciences, 9 (6),1-12.

- Norsilan, I., Omar, Z. and Ahmad, A. (2014), 'Workplace Deviant behaviour: A Review of Typology of Workplace Deviant behavior,' Middle-East Journal of Scientific Research, 34-38.

- Pletzer, J. L., Oostrom, J., Voelpel, S. C. (2017), 'Age Differences in Workplace Deviance: A Meta-Analysis,' Academy of Management Annual Meeting Proceedings, 2017 (1), 11475.

- Priesmuth, M., Schminke, M., Ambrose, M. L. and Folger, R. (2014), 'Abusive supervision climate: A multiplemediation model of its impact on group outcomes,' Academy of Management Journal, 57(5), 1513-1534.

- Rhoades, L. and Eisenberger, R. (2002), 'Perceived Organizational Support: A 
Review of the Literature,' Journal of Applied Psychology, 87(4), 698-714.

- Richard, O.C., McMillan-Capehart, A., Bhuian, S.N. and Taylor, E.C. (2009), 'Antecedents and consequences of psychological contracts: Does organizational culture really matter?,' Journal of Business Research, 62(8), 818825.

- Robinson, S. and Bennett, R. (1995), 'A Typology of Deviant Workplace Behaviors: A Multidimensional Scaling Study,' The Academy of Management Journal, 38 (2), 555-572.

- Rousseau, D. (1989), 'Psychological and implied contracts in organizations,' Employee Responsibilities and Rights Journal, 2 (2), 121-139.

- Santos, A. and Eger, A. (2014), 'Gender differences and predictors of workplace deviance behavior: The role of job stress, job satisfaction and personality on interpersonal and organizational deviance,' International Journal of Management Practice, 7(1), 19-37.
- Schein (1985), Organizational Culture and Leadership, San Francisco, JosseyBass Publishers.

- $\quad$ Sims, R. (2010), 'A study of deviance as a retaliatory response to organizational power,' Journal of Business Ethics, 92(4), 553-565.

- Spector, P. and Fox, S. (2002), 'An emotion-centered model of voluntary work behavior: Some parallels between counterproductive work behavior and organizational citizenship behavior,' Human Resource Management Review, 12(2), 269-292.

- Valentine, S., Fleischman, G. and Godkin, L. (2015), 'Rogues in the ranks of selling organizations: Using corporate ethics to manage workplace bullying and job satisfaction,' Journal of Personal Selling\&Sales Management, 35, 143-163.

- Vardi, Y. and Weitz, E. (2004), 'Misbehavior in organizations: Theory, research, and management,' Mahwah, NJ: Erlbaum. In Cchernyak-Hai, L., Kim, S-K., Tziner, A. (2018), Journal of Work and Organizational Psychology, 34(1), 46-55. 